\title{
Assistência odontológica no pais: perspectivas 1
}

\author{
José Carlos Borges Teles" "Faculdade de Odontologia \\ - UFRJ
}

Num país em que as regiões geográficas mostram discrepâncias bem evidentes de condições sócio-econômicas e de diferente distribuição de recursos de atendimento odontológico, em total dissonância com as necessidades da população para cada região em particular, a abordagem de um tema sobre Assistência Odontológica torna-se bastante complexa e difícil de ser analisada de modo a possibilitar ao leitor uma imagem da situação atual e das perspectivas vislum. bradas para o futuro, a curto, médio ou longo prazo.

Segundo dados fornecidos pelo Conselho Federal de Odontologia, em seu relatório de $1982^{5}$, o Brasil possuia um total de 70.143 cirurgiões-dentistas para atendimento a uma população de cerca de 120 milhões de habitantes. Este número global, no entanto, não revela uma distribuição equilibrada (racional) ou em consonância com as necessidades das populações menos favorecidas sob o ponto de vista econômico, tomando por base o salário mínimo vigente à época, a renda bruta per capita e as despesas inerentes ao tratamento odontológico em clínicas particulares, uma vez que as facilidades oferecidas pelos serviços públicos a nível federal, estadual ou municipal, estão longe de atender sequer a um quarto da população mais carente de recursos, que fica assim "marginalizada" do ponto de vista da saúde bucal. A distribuição de cirurgiões-dentistas é bastante desigual, e a relação dentista/paciente, em conseqüência, acompanha obviamente esta desigualdade. Assim, o quadro geral de distribuição dos odontólogos habilitados legalmente ao exercício da profissão, ainda segundo informe do CFO, era o seguinte:

\section{Região}

No de CDs

Norte . .

Nordeste .

Sudeste.

Sul . . . . . . .

Centro-Oeste

A população de cada destas regiões estava assim distri. buída:

Região

População

Norte . 
Nordeste .

Sudeste.

Sul . . . . . . .

Os números acima são irrefutáveis no sentido de demonstrar a disparidade de relação profissional/paciente para cada uma das regiões consideradas, com nitida desvantagem para as áreas de poder aquisitivo mais baixo.

Tivemos o cuidado de fazer uma análise mais aprofundada do problema, levantando o número de municípios em cada Estado (ou território) pertencente a cada uma das áreas geográficas que não possuíam nenhum ou apenas um dentista registrado nos Conselhos Regionais de Odontologia, e os números encontrados realmente são de causar preocupação, não só em relação ao momento presente como para o futuro, pois nos aliamos àqueles não muito otimistas quanto a uma mudança radical do panorama de então, acreditando mesmo que seria necessário um esforço conjunto muito bem concatenado e "missionário" entre as autoridades da área da saúde, profissionais engajados em atividades privadas, clínicas populares ou mesmo nos serviços públicos, no sentido de atender ao menos precariamente (em algumas áreas) às necessidades mínimas de saúde bucal da população brasileira.

Para que o leitor tenha uma idéia bem clara da situação, reproduzimos abaixo os números computados pelo $\mathrm{CFO}$ para cada região respectiva (também são transcritos o número de CDs existentes nas capitais e a respectiva população).

O somatório destes números aponta que havia no País, em 1982, um total de 1.538 municípios sem um dentista sequer e 756 outros em que apenas um CD poderia ser encontrado para atender às necessidades de saúde bucal da população daquele município.

A Organização Mundial da Saúde, através da chamada Unidade de Saúde Bucal, relatou por meio do Banco Mundial (informe de 1981) que o índice CPO aos 12 anos, no Brasil, era de 7,2, ocupando o 3 ? lugar como índice mais elevado, numa análise estatística em que foram incluídos 16 países de diversos continentes. Entre os países estudados, este índice só ultrapassava o do Brasil em Costa Rica $(8,3)$ e Colômbia $(7,5)$.

Considerando que atualmente o nosso país é, provavelmente, o líder mundial em Faculdades ou Escolas de Odontologia (um total de 69, incluindo as federais, estaduais e particulares), forçoso é concluir que o ensino de Graduação que vem sendo ministrado em praticamente a totalidade dessas instituições de ensino não está formando o "produto" que a sua população necessita, uma vez que os profis- 
sionais egressos, a cada ano, recebem uma formação voltada para atuar em niveis elitistas, e seus currículos são montados muito mais com objetivos cognitivos, psicomotores e afetivos, que visam muito mais à reparação dos danos causados pela doença do' que seus aspectos preventivos. (Muito embora, atualmente, seja largamente apregoada a expressão "prevenção" por um contingente considerável da comunidade odontológica brasileira, tenhamos a coragem de confes. sar que ela aparece muito mais no papel ou nos discursos das solenidades e de aberturas de jornadas, congressos, etc., do que na prática).

Região Norte

Total de Dentistas: 1.482

\begin{tabular}{lcccc}
\hline \multicolumn{1}{c}{ Estado } & $\begin{array}{c}\text { No de Municípios } \\
\text { sem nenhum CD }\end{array}$ & $\begin{array}{c}\text { No de Municípios } \\
\text { com apenas um CD }\end{array}$ & $\begin{array}{c}\text { CD’s na } \\
\text { Capital }\end{array}$ & $\begin{array}{c}\text { População na } \\
\text { Capital }\end{array}$ \\
\hline Acre & 5 & 4 & 32 & 117.113 \\
Amapá & 4 & 0 & 25 & 137.697 \\
Amazonas & 31 & 9 & 248 & 634.759 \\
Pará & 38 & 24 & 782 & 934.330 \\
Rondônia & 2 & 0 & 40 & 134.621 \\
Roraima & & & 18 & 66.769 \\
\hline
\end{tabular}

\section{Região Nordeste}

Total de Dentistas: 10.057

\begin{tabular}{lccrr}
\hline \multicolumn{1}{c}{ Estado } & $\begin{array}{c}\text { No de Municípios } \\
\text { sem nenhum CD }\end{array}$ & $\begin{array}{c}\text { No de Municípios } \\
\text { com apenas um CD }\end{array}$ & $\begin{array}{c}\text { CD's na } \\
\text { Capital }\end{array}$ & $\begin{array}{r}\text { População na } \\
\text { Capital }\end{array}$ \\
\hline Bahia & 201 & 69 & 1.414 & 1.501 .219 \\
Ceará & 49 & 40 & 967 & 1.308 .859 \\
Alagoas & 61 & 15 & 544 & 400.041 \\
Paraíba & 118 & 20 & 701 & 330.176 \\
Pernambuco & 89 & 36 & 1.716 & 1.204 .794 \\
Piauí & 65 & 26 & 345 & 378.026 \\
Maranhão & 43 & 67 & 360 & 449.877 \\
Rio Grande & & 28 & 544 & \\
do Norte & 96 & 46 & 247 & 416.906 \\
Sergipe & 15 & & & 293.485 \\
\hline
\end{tabular}

Região Sudeste

Total de Dentistas: 43.342

\begin{tabular}{lcccr}
\hline \multicolumn{1}{c}{ Estado } & $\begin{array}{c}\text { No de Municípios } \\
\text { sem nenhum CD }\end{array}$ & $\begin{array}{c}\text { No de Municípios } \\
\text { com apenas um CD }\end{array}$ & $\begin{array}{c}\text { CD s na } \\
\text { Capital }\end{array}$ & $\begin{array}{c}\text { População na } \\
\text { Capital }\end{array}$ \\
\hline Espírito Santo & 4 & 15 & 518 & 207.560 \\
Minas Gerais & 294 & 78 & 2.940 & 1.774 .712 \\
Rio de Janeiro & 5 & 6 & 6.539 & 5.093 .496 \\
São Paulo & 116 & 88 & 10.135 & 8.490 .663 \\
\hline
\end{tabular}




\section{OPINIĀO}

Região Sul

Total de Dentistas: 11.409

\begin{tabular}{lcccr}
\hline \multicolumn{1}{c}{ Estado } & $\begin{array}{c}\text { No de Municípios } \\
\text { sem nenhum CD }\end{array}$ & $\begin{array}{c}\text { No de Municípios } \\
\text { com apenas um CD }\end{array}$ & $\begin{array}{c}\text { CDs na } \\
\text { Capital }\end{array}$ & $\begin{array}{r}\text { População na } \\
\text { Capital }\end{array}$ \\
\hline Paraná & 82 & 59 & 1.110 & 1.025 .979 \\
$\begin{array}{l}\text { Santa Catarina } \\
\text { Rio Grande } \\
\text { do Sul }\end{array}$ & 55 & 51 & 453 & 187.800 \\
\hline
\end{tabular}

Região Centro-Oeste

Total de Dentistas: 3.855

\begin{tabular}{lcccc}
\hline \multicolumn{1}{c}{ Estado } & $\begin{array}{c}\text { No de Municípios } \\
\text { sem nenhum CD }\end{array}$ & $\begin{array}{c}\text { No de Municípios } \\
\text { com apenas um CD }\end{array}$ & $\begin{array}{c}\text { CD's na } \\
\text { Capital }\end{array}$ & $\begin{array}{c}\text { População na } \\
\text { Capital }\end{array}$ \\
\hline Mato Grosso & 30 & 9 & 153 & 213.151 \\
Mato Grosso & & 11 & 348 & 291.807 \\
do Sul & 10 & 30 & 884 & 717.948 \\
Goiás & 123 & 1 & 943 & 423.742 \\
Distrito Federal & 0 & & & \\
\hline
\end{tabular}

Dentre as funções que uma universidade deve desempenhar, através de seus docentes e do processo ensino/aprendizado, três se destacam, segundo o consenso unânime das autoridades máximas que as dirigem: 1) ensino; 2) pesquisa e 3) prestação de atendimento às necessidades de saúde da comunidade. Com a crise que atravessa o ensino superior em nosso país (e que cada dia vem se agravando, pela falta de sensibilidade dos dirigentes de nossa nação quanto à im. portância que o binômio saúde/educação representa para a evolução de um povo), é óbvio que a terceira destas funções nunca foi aquela que mais preocupou a mente dirigente do ensino do 3 ? grau em nosso país (e também do corpo docente). Fica assim claramente demonstrado por que o nosso povo está na atual situação de quase "calamidade" em relação à saúde bucal.

Para não cometermos injustiças, devemos esclarecer que já há alguns "núcleos" isolados de entidades de ensino odontológico e serviços públicos que começam a tomar consciência de suas responsabilidades perante a comunidade e já estão envidando esforços no sentido de alterar a mentalidade reinante em seus corpos docente e discente; a este propósito merece menção especial o trabalho desenvolvido pelo Prof. Eugênio Vilaça Mendes? que, ao ser convocado para montar o currículo do Departamento de Odontologia da Universidade Católica de Minas Gerais, organizou-o em moldes completamente diferentes dos currículos tradicionais (ainda desenvolvidos na maioria das nossas entidades de ensino na área da odontologia), onde todos os objetivos operacionais são dirigidos no sentido de dar enfoque preventivo a diferentes níveis. 
Como reforço às informações e idéias desenvolvidas até o momento, transcrevemos ipsis litteris alguns tópicos retirados do documento "Programa de Reorientação da Assistência Odontológica", elaborado pelo Ministério da Previdência e Assistência Social e publicado em 1983. ${ }^{1}$ Neste documento lê-se, entre outras, as seguintes informações elaboradas pelo CONASP (Conselho Consultivo da Administração de Saúde Previdenciária):

"No âmbito da Previdência Social, apesar de todo o avanço do conhecimento e do desenvolvimento tecnológico, a assistência odontológica sempre foi incipiente se comparada à assistência médica, embora com variações de Instituto para Instituto antes da consolidação do INPS ( $e$ apesar dela; o adendo e grifo são do autor). De qualquer forma, sempre predominaram as ações assistenciais e não as preventivas, sendo que aquelas, na sua maioria, de caráter mutilador, ou sejam, extrações dentárias".

No que toca ao quadro epidemiológico, "por ordem de prioridade, os principais problemas de saúde bucal são:

1) cárie dental;

2) doença periodontal;

3) deformidades dento-faciais (problemas de posição dos dentes);

4) lábio leporino e fenda palatina;

5) câncer na boca".

Antes de prosseguirmos citando outros informes contidos naquele documento, permitimo-nos fazer um breve comentário que será objeto de análise mais detalhada um pouco adiante: por que colocar os itens 3 e 4 e relegar o problema do câncer bucal para a 5 a prioridade como problema de saúde bucal, quando, um pouco adiante, informam: " $O$ câncer da boca, por sua vez, incide com alta malignidade, observando-se que $8,5 \%$ dos tumores malignos em homens e $2,3 \%$ em mulheres têm sua ocorrência na boca". Aqui também, na qualidade de docente devotado à área da Patologia Bucal, o autor vê-se constrangido a ter que assumir uma posição pouco confortável de crítica ao uso da expressão "alta malignidade"; seria preferível adotar o termo "prevalência" em substituição a "malignidade", pois este tem uma significação completamente diferente da que os responsáveis pela elaboração do documento empregaram.

Como pensar em oferecer atendimento aos portadores dos defeitos de oclusão e aos portadores de lábio leporino e fenda palatina, quando no documento são ressaltados o alto custo e a complexidade do tratamento de tais patologias.

Um outro tópico merece transcrição: "A tradição liberal que tem caracterizado a odontologia brasileira, a par de tê-la conduzido à obtenção de elevados níveis qualitativos, 
não conseguiu solucionar satisfatoriamente a questão fundamental da extensão dos serviços clínicos e preventivos aos extensos contingentes populacionais de menor renda. Neste sentido, estima-se que cerca de $75 \%$ do tempo dos CDs do País estejam alocados a atividades privadas".

A assistência odontológica prestada no âmbito da Previdência Social oferece, no entanto, baixa cobertura populacional ( $0,32 \%$ consultas/habitante/ano), com a distribuição geográfica e demográfica distorcida, acompanhando as mesmas tendências da assistência médica em geral. Por outro lado, a assistência prestada, baseada em um modelo extremamente caro, que privilegia as ações curativas em detrimento das preventivas, não consegue dar adequada resolutividade, com alta taxa de atos mutiladores (extrações dentárias), em relação às ações conservadoras e reparadoras (restaurações, etc.). Assim, 50\% dos serviços odontológicos prestados em nível ambulatorial correspondem a extrações". O trecho acima, reproduzido de documento publicado pelo Ministério da Previdência e Assistência Social, mostra com clareza a precariedade dos serviços oferecidos no campo odontológico aos contribuintes da previdência social em nosso país. Nesta mesma fonte informa-se que o "INAMPS emprega cerca de 2.500 odontólogos e credencia 5.600 ambulatórios", acrescentando que "mais de $70 \%$ dos serviços odontológicos do INAMPS são oferecidos pela iniciativa privada contratada ou convencionada". Não informa a utilização de prestação de serviços de pessoal auxiliar que beneficiaria sobremodo a um percentual maior da população carente, com redução acentuaḍa dos gastos, que em 1981 somaram 3,7 bilhões de cruzeiros, para um atendimento a apenas 10 milhões de beneficiários.

Pereira, ${ }^{8}$ na atualidade uma das mais conceituadas autoridades brasileiras no campo de assistência odontológica à comunidade, enfoca de maneira irrefutavelmente clara que a utilização de pessoal auxiliar não só acarreta uma redução considerável nos custos, como propicia um atendimento melhor para um contingente da população na faixa etária em que a incidência da cárie dental é das mais elevadas (6. 12 anos). Em circunstanciado e bem elaborado quadro demonstrativo, este autor, através de experiência própria no trabalho que vem desenvolvendo no Distrito Federal, no Projeto Saúde Bucal da Fundação Educacional do Distrito Federal, com apoio de outras entidades, desde 1978, comprova que a utilização da mão-de-obra de auxiliares odontológicos bem poderia servir como modelo para sua adoção em todo território nacional, para o sistema da assistência odontológica pela Previdência Social, Secretarias Estaduais e Municipais da Saúde, etc. Tivessem todos os profissionais envolvidos no atendimento odontológico de serviços públi- 
cos e de clínicas a mesma visão deste profissional, talvez, num futuro bem próximo, pudéssemos ler um tex to bem diferente daquele que é encontrado na introdução do artigo de Pereira ${ }^{8}$ que, com a devida vênia do autor, transcrevemos: "Três em cada quatro brasileiros perdem todos os dentes naturais até os sestenta anos de idade em conseqüência das cáries. Aos seis anos as crianças já apresentam, em média, 1,6 dentes permanentes atacados pela cárie.

Aos sete anos, esse número chega a quase três dentes $(2,78)$ e, quando a criança alcança os quatorze anos, apresenta 10,2 dentes cariados. Entre quatorze e cinqüenta anos, a média é de 24,7 dentes cariados.

As cáries estão presentes, hoje, em 600 milhões de dentes, $90 \%$ dos quais jamais serão recuperados, por total falta de assistência. Essa condição ocorre com mais freqüência entre as camadas mais pobres da população, que quase não têm acesso aos serviços de assistência odontológica".

Que tal uma reflexão sobre os dois parágrafos acima por parte de todos os responsáveis pela saúde bucal de nosso povo, nos dias que correm?!

Trabalho semelhante e digno dos maiores encômios, por representar uma tentativa de mudança de atitude face aos reclamos de um estrato economicamente desfavorecido, residindo na área do campus da UFRJ, vem sendo desenvolvido pela Disciplina de Odontopediatria da FO - UFRJ, através de projeto de saúde bucal elaborado e já em funcionamento, sob a direção geral do Prof. Roberto Vianna e contando com a inestimável cooperação e nunca suficientemente exaltada abnegação da Profa Hosana Glória dos Santos.

Por último, gostaríamos de tecer alguns comentários sobre a situação do câncer bucal no Brasil, como problema de saúde pública. Segundo dados retirados de publicação sobre o câncer no Brasil, no qüinqüênio de 1976-80, a situação do câncer bucal em relação à distribuição percentual relativa das dez localizações mais freqüentes, segundo as diferentes regiões do corpo, era a seguinte: homem - 3 \% lugar, com $8,5 \%$ de todos os casos, e mulher 7 \% lugar, com $2,3 \%$ de todos os casos. Naquele mesmo período, o total de diagnósticos primários nos dois sexos foi o seguinte: homem 170.541 e mulher -199.226 .

Em números, o total de diagnósticos de câncer primário envolvendo a boca e faringe foi de 19.270 no sexo masculino e 5.506 no sexo feminino.

Considerando a distribuição segundo as diferentes regiōes da boca, o quadro apresentado é o seguinte:

Caderṇos de Saúde Pública, R.J., 1 (2), abr/jun, 1985. 


\begin{tabular}{lrr}
\hline & Homem & Mulher \\
\hline Lábio & 4.160 & 997 \\
Língua & 4.304 & 1.072 \\
Glândula salivar maior & 659 & 502 \\
Gengiva e outras partes & 4.152 & 1.689 \\
Assoalho da boca & 1.227 & 315 \\
\hline
\end{tabular}

Os números e percentuais acima, contudo, não traduzem a situação real do problema do câncer bucal na população brasileira, pois são baseados em informes remetidos por centros de serviço de anatomia patológica, que não abrangem, na área da odontologia, nem 50\% do global das Faculdades de Odontologia existentes no país. Assim, é preciso que o enfoque do problema do câncer bucal comece a ser, o mais rapidamente possível, objeto de preocupação por parte das instituições de ensino, serviços odontológicos, etc.

Esta situação é ainda mais agravada quando se sabe que um percentual considerável dos recém-graduados em odontologia recebem seus diplomas sem terem sequer executado uma biópsia ou uma citologia exfoliativa e acompanhado um caso de câncer. Com a criação da disciplina de Diagnóstico (e/ou Semiologia Oral), e o entrosamento da mesma com um Laboratório de Patologia Oral, em algumas Faculdades de Odontologia, foi possível incutir na mente dos graduandos a responsabilidade que lhes cabe, como profissionais integrantes do sistema de saúde, no diagnóstico precoce do câncer bucal.

Em 1976, a Divisão Nacional do Câncer do Ministério da Saúde, em colaboração com a Sociedade Brasileira de Estomatologia, elaborou um Documento Básico Inicial, no qual uma comissão constituída por docentes e profissionais de reconhecida autoridade, militantes nas áreas de Diagnóstico, Patologia e Medicina Bucal, traçou as metas básicas a serem alcançadas com o objetivo específico de desenvolver um "Programa Nacional de Prevenção e Diagnóstico Precoce do Câncer Bucal - CABUL". 3

Naquele documento, entre outras justificativas e objetivos preconizados pela comissão que o elaborou, destacam-se os seguintes tópicos:

1) O enfoque do câncer bucal como problema de saúde pública, por constituir causa comum de mortalidade, considerando a existência de métodos eficazes de prevenção e controle, os quais não estão sendo utilizados de modo adequado.

2) A tecnologia de saúde aplicada ao diagnóstico precoce e tratamento oportuno do câncer bucal não está sendo utilizada adequadamente em termos de eficiência, pois tal 
tecnologia alcançará melhor seus objetivos quando aplicada nos estágios precoces da evolução do câncer bucal.

3) As fases tardias da história natural do câncer bucal requerem uma tecnologia avançada, não disponivel em todas as regióes do território nacional em quantidade e qualidade desejáveis, sendo, assim, um fator limitante de alta relevância.

4) Alcançar eficiência e eficácia com a tecnologia disponível, no sentido de diagnosticar precocemente os casos de câncer bucal.

5) Reconhecer os níveis e estruturas de saúde no que se refere ao câncer bucal e adestrar os recursos humanos em relação ao mesmo, de modo a reduzir o impacto da doença em fase avançada na população economicamente ativa, bem como atenuar o seu custo social.

6) Buscar o envolvimento da comunidade no planejamento, através de ação integrada.

7) Estabelecer um sistema de Módulos de Serviço, de complexidade crescente, levando em consideração as características biof ísicas e sócio-culturais das diversas regiões do país.

Por razões que o autor desconhece, este bem elaborado anteproje to não foi posto em execução e deve ter morrido (mesmo antes de nascer) nas emperradas gavetas dos gabinetes dos altos dirigentes responsáveis pelos serviços de saúde do sofrido povo brasileiro.

\section{REFERENCIAS BIBLIOGRÁFICAS}

1. BRASIL. Ministério da Previdência e Assistência Social. Programa de reorientação da assistência odontológica. Rio de Janeiro, MPAS/CCS, 1983.

2. __ Reorientação da assistência à saúde no âmbito da previdência social. 3.ed. Brasilia, 1983.

3. BRASIL. Secretaria Nacional de Saúde. Programa nacional de prevenção e diagnóstico precoce do câncer bucal - CABUL. Brasilia, 1976. (Documento básico inicial).

4. BRASÍlIA. Secretaria de Educação e Cultura. Programa integrado de saúde escolar. Brasília, 1983.

5. CONSELHO FEDERAL DE ODONTOLOGIA. Relatório, 1982. 
OPINIĀO

6. GARRAFA, V. Contra o monopólio da saúde. Rio de Janeiro, Achiamé, 1983.

7. MENDES, E.V. $O$ espectro do ensino (depoimento exclusivo). $R G O, 28$ (3) : 176-8, jul./set., 1980.

8. PEREIRA, S. Cuidados primários em saúde bucal. $A$ Saúde no Brasil, 1 (2) :89-95, abr./jun., 1983. 